\title{
Transbilayer Mobility and Distribution of Red Cell Phospholipids during Storage
}

\author{
Danielle Geldwerth, * Frans A. Kuypers, ${ }^{*}$ Peter Bütikofer, ${ }^{5}$ Michel Allary, ${ }^{*}$ Bertram H. Lubin, and Philippe F. Devaux * \\ *Institut de Biologie Physico-Chimique, Paris, France; ${ }^{\ddagger}$ Centre de Transfusion Sanguine des Armées "Jean Julliard," Clamart, France; \\ and ${ }^{\S}$ Children's Hospital Oakland Research Institute, Oakland, California 94609
}

\begin{abstract}
We studied phospholipid topology and transbilayer mobility in red cells during blood storage. The distribution of phospholipids was determined by measuring the reactivity of phosphatidylethanolamine with fluorescamine and the degradation of phospholipids by phospholipase $A_{2}$ and sphingomyelinase $C$. Phospholipid mobility was measured by determining transbilayer movements of spin-labeled phospholipids. We were unable to detect a change in the distribution of endogenous membrane phospholipids in stored red cells even after 2-mo storage. The rate of inward movement of spin-labeled phosphatidylethanolamine and phosphatidylserine was progressively reduced, whereas that for phosphatidylcholine was increased. These changes in phospholipid translocation correlated with a fall in cellular ATP. However, following restoration of ATP, neither the rate of aminophospholipid translocation nor the transbilayer movement of phosphatidylcholine were completely corrected. Taken together, our findings demonstrate that red cell storage alters the kinetics of transbilayer mobility of phosphatidylserine, phosphatidylethanolamine, and phosphatidylcholine, the activity of the aminophospholipid translocase, but not the asymmetric distribution of endogenous membrane phospholipids, at least at a level detectable with phospholipases. Thus, if phosphatidylserine appearance on the outer monolayer is a signal for red cell elimination, the amount that triggers macrophage recognition is below the level of detection upon using the phospholipase technique. (J. Clin. Invest. 1993. 92:308-314.) Key words: red cells • storage • lipid asymmetry • aminophospholipid translocase
\end{abstract}

\section{Introduction}

With modern-day anticoagulants that preserve the metabolic activity of red cells, blood can be stored for a maximum of $35 \mathrm{~d}$ at $4^{\circ} \mathrm{C}$. Storage beyond this time results in intracellular defects that shorten posttransfusion survival below the acceptable recovery rate of $70 \%$ at $24 \mathrm{~h} \mathrm{(1).} \mathrm{Although} \mathrm{many} \mathrm{abnormalities}$ have been identified in stored red blood cells (RBCs), the precise irreversible cellular change or changes responsible for the decline in their viability after transfusion have not been established (2-4).

Address correspondence to Dr. Danielle Geldwerth, Institut de Biologie Physico-Chimique, 13 rue Pierre et Marie Curie, Paris, France.

Dr. Peter Bütikofer's present address is Institute of Biochemistry \& Molecular Biology, University of Bern, 3012 Bern, Switzerland.

Received for publication 30 April 1992 and in revised form 11 January 1993.

J. Clin. Invest.

(C) The American Society for Clinical Investigation, Inc. 0021-9738/93/07/0308/07 \$2.00

Volume 92, July 1993, 308-314
While certain similarities between stored red cells and senescent red cells such as an increase in membrane associated globin (5), the loss of membrane lipids $(4,6,7)$, the oxidation of skeletal proteins, loss of cellular antioxidant capability (5, 8-10), and the appearance of "senescent antigen"-like structures (11) have led to the suggestion that the red cells in stored blood are merely prematurely old, this seems too broad a characterization. For example, the reversibility of several of the metabolic and morphologic characteristics of stored blood upon ATP repletion distinguishes the stored from the senescent cell $(2,12)$. Furthermore, events that characterize in vivo aging, such as the interactions between reticuloendothelial cells and RBCs resulting in membrane remodeling, do not occur during blood storage. It is conceivable that stored red cells could have a more normal life span if the key change or changes that lead to their cellular and/or metabolic defects could be found.

Relatively little attention has been given to phospholipid distribution and dynamics in the membrane of stored cells and their possible contribution to decreasing posttransfusion viability of these cells. In the normal red cell, the transmembrane distribution of phospholipids is asymmetric: phosphatidylcholine (PC) $)^{1}$ and sphingomyelin (SM) are predominantly located in the outer monolayer, whereas most of the phosphatidylethanolamine (PE) and practically all of the phosphatidylserine (PS) are in the inner monolayer $(13,14)$. Aminophospholipid asymmetry is maintained by a Mg-ATPase enzyme, called the aminophospholipid translocase, which continuously pumps PS and PE from the outer to the inner leaflet of the membrane (14-16). Additional cytoskeletal protein interactions between PS and spectrin and/or band 4.1 may help to stabilize PS asymmetry (17-19), but these protein interactions appear to be less important than the aminophospholipid translocase in maintaining phosphatidylserine asymmetry $(20,21)$.

Several studies suggest that RBCs and lymphocytes that have been modified so that they have phosphatidylserine on their outer leaflet bind more readily to macrophages than normal RBCs and lymphocytes do (22-25). Thus, if PS asymmetry were lost during storage, the viability of RBCs could be decreased $(25,26)$. One mechanism which could result in loss of phospholipid asymmetry would be a decrease in the activity of the aminophospholipid translocase. Because the aminophospholipid translocase activity is decreased in ATP-depleted red cells and in oxidized red cells in vitro $(14,27)$, conditions

1. Abbreviations used in this paper: CPD, citrate-phosphate-dextrose; EPR, electron paramagnetic resonance; PAGGSS, phosphate-adenineguanosine-glucose-saline-sorbitol; PC, phosphatidylcholine; PC*, 1palmitoyl-2-(4-doxylpentanoyl)phosphatidylcholine; PE, phosphatidylethanolamine; PE*, 1-palmitoyl-2-(4-doxylpentanoyl)phosphatidylethanolamine; PS, phosphatidylserine; PS*, 1-palmitoyl-2-(4doxylpentanoyl)phosphatidylserine; SM, sphingomyelin. 
also known to exist in stored blood $(3,28)$, we designed experiments to test whether there are changes in phospholipid asymmetry and aminophospholipid translocase activity in blood that had been stored at low temperature for up to $60 \mathrm{~d}$. Our study demonstrates that long-term storage does induce changes in the transbilayer mobility of spin-labeled phospholipids resulting eventually in modifications of the distribution of these lipids, yet these changes are not accompanied by a detectable loss of asymmetry of endogenous phospholipids.

\section{Methods}

Storage of human RBCs. Blood was drawn from healthy donors. Closed double or triple bag systems were used. Approximately $450 \mathrm{ml}$ of blood was drawn into the primary bag containing $63 \mathrm{ml}$ of a standard CPD anticoagulant solution. Immediately after centrifugation at 6,000 $g$ for $10 \mathrm{~min}$, the plasma and buffy coat were expelled into the empty satellite bag. Pelleted cells were stored either without further addition at $80 \%$ hematocrit (CPD samples) or resuspended to a hematocrit of $66 \%$ in $100 \mathrm{ml}$ of a PAGGSS solution (Biotest Pharma, Frankfurt, Germany), containing $8 \mathrm{mM} \mathrm{NaH}_{2} \mathrm{PO}_{4}, 8 \mathrm{mM} \mathrm{Na}_{2} \mathrm{HPO}_{4}, 1.5 \mathrm{mM}$ adenine hydrochloride, $1.4 \mathrm{mM}$ guanosine, $47 \mathrm{mM}$ glucose, $72 \mathrm{mM} \mathrm{NaCl}$, $55 \mathrm{mM}$ sorbitol, pH 6.5 (PAGGSS sample) (29). RBCs were stored for $60 \mathrm{~d}$ at $4^{\circ} \mathrm{C}$ unless otherwise indicated. In some experiments, stored RBCs had their ATP repleted by incubation for $4 \mathrm{~h}$ at $37^{\circ} \mathrm{C}$ in a buffer containing $10 \mathrm{mM}$ Hepes, $90 \mathrm{mM} \mathrm{NaCl}, 50 \mathrm{mM} \mathrm{Na}_{2} \mathrm{HPO}_{4}, 5 \mathrm{mM}$ $\mathrm{KCl}, 1 \mathrm{mM} \mathrm{MgCl}$, $0.5 \mathrm{mM}$ EGTA, $10 \mathrm{mM}$ glucose, $10 \mathrm{mM}$ inosine, $10 \mathrm{mM}$ adenosine, $\mathrm{pH} \mathrm{7.4,} \mathrm{at} \mathrm{a} 4 \%$ hematocrit.

Measurement of intracellular ATP concentration. Stored cells were washed three times and diluted to a $30 \%$ hematocrit in $0.9 \% \mathrm{NaCl}$. ATP was extracted from the diluted suspension in $0.5 \%$ trichloroacetic acid, $2 \mathrm{mM}$ EDTA, and measured (30) using a luciferin-luciferase assay (Pharmacia LKB, Uppsala, Sweden).

Assessment of phospholipid distribution in the RBC membrane. Distribution of endogenous membrane phospholipids was determined by using phospholipase $A_{2}$ from bee venom (Boehringer Mannheim $\mathrm{GmbH}$, Mannheim, Germany) and sphingomyelinase C from Staphylococcus aureus (Sigma Chemical Corp., St. Louis, MO). The procedure was performed as described $(31,32)$, except that $0.2 \mathrm{ml}$ of RBCs was suspended in $5 \mathrm{ml}$ of $50 \mathrm{mM}$ PBS buffer containing $5 \mathrm{mM} \mathrm{KCl}$, $0.25 \mathrm{mM} \mathrm{MgCl}_{2}, 0.5 \mathrm{mM} \mathrm{CaCl}_{2}, \mathrm{pH}$ 7.4. In experiments using both enzymes, samples were first incubated for $1 \mathrm{~h}$ at $37^{\circ} \mathrm{C}$ with $50 \mathrm{IU}$ of phospholipase $\mathrm{A}_{2}$ and an additional $0.5 \mathrm{~h}$ at $37^{\circ} \mathrm{C}$ with $1.2 \mathrm{IU}$ of sphingomyelinase $\mathrm{C}$. In experiments to determine SM distribution in the bilayer, no phospholipase $A_{2}$ was added for the first hour incubation at $37^{\circ} \mathrm{C}$. Incubations were terminated by low-speed centrifugation followed by lysis of the cells by a $5 \mathrm{mM}$ EDTA solution. The extent of hemolysis was measured at the end of each incubation before EDTA was added. Lipid extracts of enzyme-treated and control samples were prepared as described by Rose and Oklander (33). Lipids were separated by two-dimensional TLC (34), and the amount of phospholipid phosphorus present in each spot after visualization in iodine was determined according to Rouser et al. (35). Each sample for phospholipase assay was analyzed in duplicate.

In addition, the bilayer distribution of endogenous PE was measured by fluorescamine labeling (36). Briefly, RBCs were washed three times with saline and resuspended in labeling buffer $(100 \mathrm{mM} \mathrm{KCl}, 50$ $\mathrm{mM} \mathrm{NaCl}, 1 \mathrm{mM} \mathrm{CaCl}, 1 \mathrm{mM} \mathrm{MgCl} 2,5 \mathrm{mM} \mathrm{Na}_{2} \mathrm{CO}_{3}, 20 \mathrm{mM}$ Tricine, pH 8.0). Subsequently, fluorescamine was added to $1.3 \times 10^{9}$ $\mathrm{RBC}$ in $3.3 \mathrm{ml}$ of buffer from a $114 \mathrm{mM}$ stock solution in DMSO/acetone (1:2.5). Labeling was carried out at room temperature for $30 \mathrm{~s}$ while the cells were spun in a vortex. The reaction was stopped by adding $7.5 \mathrm{ml}$ of the labeling buffer that contained $6 \mathrm{mM}$ glycylglycine (instead of $\mathrm{Na}_{2} \mathrm{CO}_{3}$ ) and spinning them in a vortex for $30 \mathrm{~s}$. RBCs were pelleted by low-speed centrifugation and lysed by adding $0.5 \mathrm{ml}$ of 20 $\mathrm{mM}$ glycylglycine, $\mathrm{pH}$ 8.0. Lipid extracts were obtained according to the method of Rose and Oklander (33). Lipids were separated by one-di- mensional TLC in $\mathrm{CHCl}_{3} / \mathrm{MeOH} / \mathrm{H}_{2} \mathrm{O} / \mathrm{AcOH}$ (100:44.4:2.2:13.3). Fluorescamine-labeled PE was visualized under the ultraviolet lamp, and lipid spots were identified using iodine vapor. All spots were removed from the plate by scraping, and phospholipid phosphorus was measured as described (35). The percentage of fluorescamine-labeled $P E$ was calculated from the phosphorus data for fluorescamine-labeled $\mathrm{PE}$ and unlabeled PE, and plotted versus the fluorescamine/ phospholipid ratio on a semi-logarithmic scale.

Measurement of aminophospholipid translocase activity. The activity of the aminophospholipid translocase was determined by measuring the transbilayer redistribution of spin-labeled aminophospholipids in RBCs incubated at $37^{\circ} \mathrm{C}$. The spin-labeled phospholipids used throughout this study possessed a short fatty acid $\beta$ chain (five carbon atoms) bearing a nitroxide at the fourth carbon position. The short chain provides partial water solubility to the lipid molecules. This facilitates their incorporation into the membranes and allows one to monitor lipid translocation by electron paramagnetic resonance (EPR) using an EPR spectrometer (model E9; Varian Associates, Inc., Palo Alto, CA) after extraction with BSA of the probes outwardly exposed (37). During the assay, RBCs were resuspended at $20 \%$ hematocrit in a buffer containing $10 \mathrm{mM}$ Hepes, $145 \mathrm{mM} \mathrm{NaCl}, 5 \mathrm{mM} \mathrm{KCl}, 1 \mathrm{mM}$ $\mathrm{MgCl}_{2}, 0.5 \mathrm{mM}$ EGTA, $10 \mathrm{mM}$ glucose, $\mathrm{pH} 7.4$. The synthesis of the spin-labeled phosphatidylcholine $\left(\mathrm{PC}^{*}\right)$, phosphatidylethanolamine $\left(\mathrm{PE}^{*}\right)$, and phosphatidylserine (PS*) has been described elsewhere $(15,37)$.

Preparation of ATP-depleted RBCS. After three washes in saline, red cells were diluted to a $10 \%$ hematocrit in a buffer containing 10 $\mathrm{mM}$ Hepes, $145 \mathrm{mM} \mathrm{NaCl}, 5 \mathrm{mM} \mathrm{KCl}, 0.5 \mathrm{mM}$ EGTA, pH 7.4, and incubated for $24 \mathrm{~h}$ at $37^{\circ} \mathrm{C}$. At the end of this incubation, cells were washed and resuspended in the appropriate buffers to measure ATP content and the availability of phospholipids to phospholipase-induced hydrolysis and fluorescamine labeling.

\section{Results}

Red cells from the first donor were stored at a hematocrit of $66 \%$ in a PAGGSS solution for up to $60 \mathrm{~d}$ under sterile, blood bank conditions. At different time intervals, aliquots were withdrawn from the storage bag; the red cells were isolated and washed three times. Washed cells were then subjected to two series of phospholipid measurements: membrane phospholipid organization and inward movement of spin-labeled phospholipid analogs. These measurements required incubation at $37^{\circ} \mathrm{C}$ for up to $1.5 \mathrm{~h}$ ( phospholipase) to several hours ( spin-labeled phospholipids). Hence, our results show the phospholipid organization in red cells that were incubated for short time periods at $37^{\circ} \mathrm{C}$ after they had been stored for prolonged periods at low temperature $\left(4^{\circ} \mathrm{C}\right.$ or $\left.7^{\circ} \mathrm{C}\right)$.

Membrane phospholipid organization. The percentage of phospholipids hydrolyzed after different periods of storage is shown in Fig. 1. The results were corrected for hemolysis, which never exceeded 5\% during the incubations with the phospholipases. The percentages of SM and PC hydrolyzed remained virtually constant. Although there appeared to be a slight increase in phosphatidylethanolamine in the outer monolayer, these changes were not significant. The distribution of PE within the inner and outer leaflet of the bilayer, as measured by fluorescamine binding, also did not change during storage (data not shown). No external leaflet PS could be detected even after 2 mo of storage (data not shown), whether fluorescamine or phospholipase techniques were used. Thus, storage appeared to have no effect on endogenous phospholipid asymmetry using these probes.

Inward movement of spin-labeled phospholipids. The translocation of the spin-labeled aminophospholipids PS* and PE* 


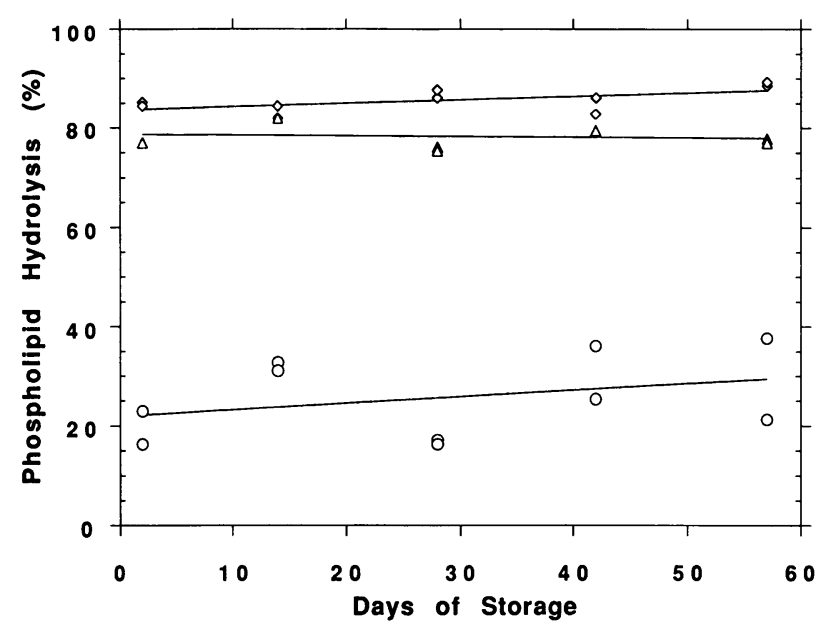

Figure 1. Percentage of RBC phospholipids hydrolyzed by phospholipase $A_{2}$ and sphingomyelinase $C$ as a function of days of storage in PAGGSS solution at $4^{\circ} \mathrm{C}(\triangle) \mathrm{PC} ;(\diamond), \mathrm{SM} ;(\circ)$, PE. Hydrolysis experiments were carried on in duplicate for each assay.

from the outer to the inner leaflet after 3,29, and $59 \mathrm{~d}$ of storage, at $4^{\circ} \mathrm{C}$, in PAGGSS is shown in Fig. 2. For the fresh cells (day 3 ), plateau values corresponding to $87 \%$ PS* and $80 \% \mathrm{PE}^{*}$ on the inner monolayer were seen. With longer storage, the translocation of the spin-labeled aminophospholipids changed, as indicated in particular by the decrease in initial slopes of the kinetics curves. In the case of PS*, after 1-mo storage at $4^{\circ} \mathrm{C}$, a plateau slightly below the initial value was reached within $1 \mathrm{~h}$ of incubation at $37^{\circ} \mathrm{C}$. After 2 mo of storage, a plateau corresponding to $70-75 \%$ PS* inside was barely attained even after 5-h incubation at $37^{\circ} \mathrm{C}$. For PE*, after $1 \mathrm{mo}$ of storage, the observed plateau was consistent with a random distribution (i.e., $50 \%$ inside), while after a 2-mo storage at $4^{\circ} \mathrm{C}$, no plateau was reached even when incubations were carried out for $5 \mathrm{~h}$ at $37^{\circ} \mathrm{C}$. The reduced ATP content of the stored red cells was certainly used up quickly during the incubation at $37^{\circ} \mathrm{C}$, making it difficult for the probes to attain their equilibrium distribution. This is certainly true after 2 mo of storage, but may even explain partly the shapes of the kinetics curves obtained after 1 mo.

Similar to our previously reported results (15), the inward movement of phosphatidylcholine in fresh cells was much slower than that of the aminophospholipids. Although a meaningful plateau was never obtained in less than $10 \mathrm{~h}$ for spin-labeled PC*, a slight increase in transbilayer movement of the $\mathrm{PC}$ analog was noted during storage as indicated by the small increase of the initial rate of transbilayer mobility (Fig. $3 B$ ). As indicated in Fig. $2 B$, the aminophospholipid inward movement after 2 mo of storage remained considerably faster than that of the PC analog.

A similar set of experiments were conducted on blood samples from three additional donors, but in CPD at a slightly higher temperature $\left(7^{\circ} \mathrm{C}\right)$. These conditions were chosen because they accelerated the effects of storage, in particular ATP depletion, and, from a technical standpoint, it facilitated our experimental approach. Due to variation in the initial ATP content of the different samples, initial velocities of phospholipid transbilayer movement following storage were expressed for each sample relative to values at the beginning of storage. Results were then averaged. Fig. 3 shows the change in initial
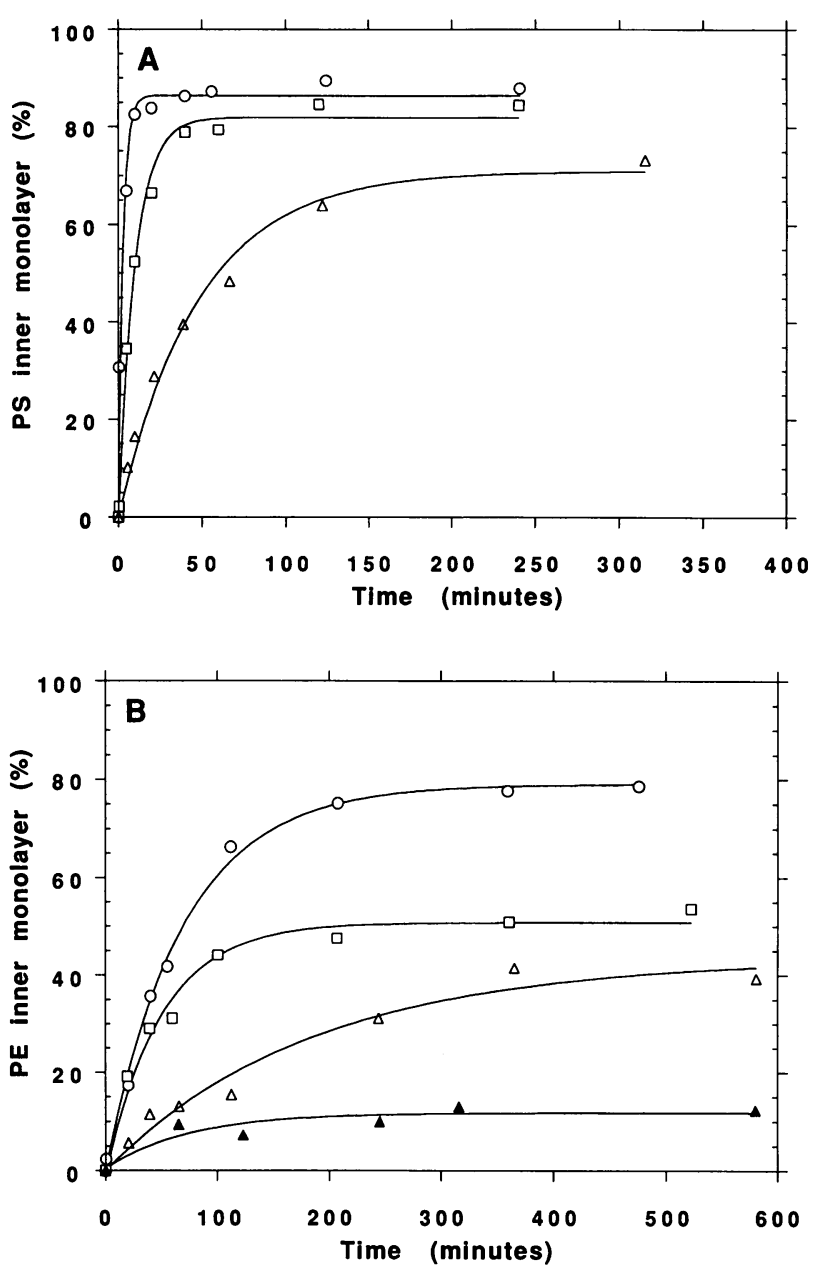

Figure 2. Redistribution kinetics at $37^{\circ} \mathrm{C}$ of spin-labeled phospholipids in RBCs after $3(O), 29(\square)$, and $59(\triangle, \triangle)$ days of storage at $4^{\circ} \mathrm{C}$ in PAGGSS: $(A)$, PS; $(B), \operatorname{PE~}(0, \square, \Delta)$; and PC $(\triangle)$. Experimental data were fitted to an exponential function by least square nonlinear regression.

velocity of the translocation as a function of storage for the spin-labeled lipids. The declines noted for spin-labeled PS* and PE* (Fig. $3 A$ ), as well as the small increase noted for spin-labeled PC* (Fig. $3 B$ ), were similar to the results obtained for these phospholipids on the PAGGSS sample. Also, the alteration in equilibrium distribution noted for both aminophospholipids was similar to the results described with PAGGSS at $4^{\circ} \mathrm{C}$.

Correlation between ATP content, translocase activity, and membrane phospholipid organization. After 2 mo of storage at $4^{\circ} \mathrm{C}$ in PAGGSS or $30 \mathrm{~d}$ at $7^{\circ} \mathrm{C}$ in CPD, the ATP levels decreased to less than $20 \%$ of their initial value (Fig. $4 A$ ). Despite the significant ATP depletion, we found no change in the distribution of endogenous phospholipids as measured by phospholipase hydrolysis (Fig. 1). To enable us to compare results from spin-labeling studies that were performed on stored blood incubated at $37^{\circ} \mathrm{C}$ up to $8 \mathrm{~h}$, with those from phospholipase studies that required only $1.5 \mathrm{~h}$ at $37^{\circ} \mathrm{C}$, we incubated aliquots of stored blood samples for $8 \mathrm{~h}$ at $37^{\circ} \mathrm{C}$ under conditions used for spin-labeling studies. These samples were subsequently analyzed for phospholipid asymmetry using phospholipases as probes as well as for ATP content. Analysis of the data on 

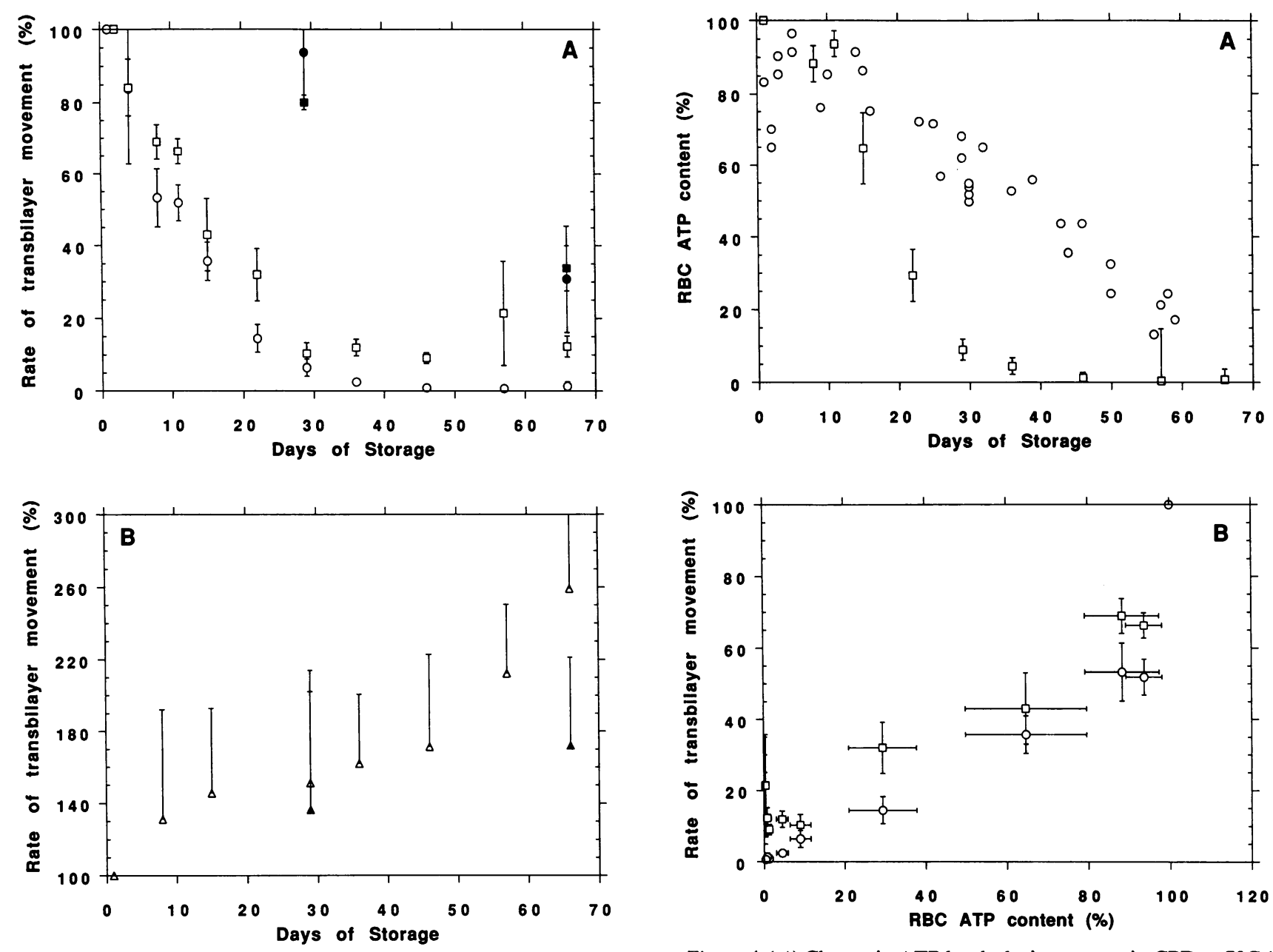

Figure 3. Change in initial velocity of inward movement of spin-labeled phospholipids in RBCs at $7^{\circ} \mathrm{C}$ in CPD during storage. $(A)$ PS $(0)$ and PE $(\square)$, and $(B) \operatorname{PC}(\triangle)$, before (open symbols) and after (solid symbols) ATP repletion. All data are expressed relative to the initial values. Average and standard deviation were calculated from the relative values obtained from three different blood samples.

endogenous phospholipid distribution demonstrated no change in lipid asymmetry under these conditions even though extreme ATP depletion was noted (data not shown). Similar results were obtained with fresh but ATP-depleted red cells. Transbilayer distribution of endogenous phospholipids in these cells is identical to the one in non-ATP-depleted fresh cells, and is not modified by further incubation of $8 \mathrm{~h}$ at $37^{\circ} \mathrm{C}$ under conditions used for the spin-labeling studies (data not shown).

The relationship between ATP level and the initial velocity of aminophospholipid translocase in the CPD storage experiment is shown in Fig. $4 \mathrm{~B}$. Similar results were obtained with blood stored in PAGGSS. The results demonstrate that the velocities of inward movement of PE* and PS* decrease as the level of ATP falls during storage. As found after partial heat denaturation (20) or after in vivo aging (27), when the aminophospholipid translocase activity diminishes, PS transport is less affected than PE transport. To determine whether factors in addition to ATP depletion affected the transbilayer movements of phospholipids, we evaluated the effect of ATP reple-

Figure 4. (A) Change in ATP levels during storage in CPD at $7^{\circ} \mathrm{C}(\square)$ or PAGGSS at $4^{\circ} \mathrm{C}(O)$. (B) Correlation between the ATP level during storage in CPD at $7^{\circ} \mathrm{C}$ and the initial velocity of inward movement of PE ( $\square$ ) and PS (O). All data are expressed relative to the initial values. Average and standard deviation were calculated from the relative values obtained for the three different blood samples stored in CPD.

tion on translocase activity and PC mobility in the red cells that had been stored for 30 and $66 \mathrm{~d}$ at $7^{\circ} \mathrm{C}$ in CPD. Incubation of these cells for $4 \mathrm{~h}$ at $37^{\circ} \mathrm{C}$ in a buffer containing glucose, phosphate, adenosine, and inosine, raised, in both cases, the ATP concentration to five times its value in fresh cells. The translocase activity is shown in these cells in the closed symbols of Fig. $3, A$ and $B$. In cells that had been stored for $30 \mathrm{~d}$, the values for both aminophospholipids were restored to at least $80 \%$ of their initial levels. In contrast, ATP repletion after $66 \mathrm{~d}$ of storage, although it restores ATP level as well as after 1 mo of storage, could only restore translocase activity for either aminophospholipid to about $30 \%$ of the initial value. The failure to completely restore aminophospholipid translocase activity suggests permanent impairment of the translocase under these storage conditions. Regarding increased inward movement of PC that accompanied storage, ATP repletion allowed us again to recover only partially the initial characteristics of transport. Nevertheless, the partial recovery of PC transbilayer movement was surprising since PC transport, in fresh cells, is not sensitive to ATP concentrations (15). 


\section{Discussion}

Several changes in RBC characteristics are known to occur during storage, a number of which could affect phospholipid organization. Stored red cells become depleted of ATP (3), undergo spheroechinocytic shape transformation (38), have abnormal calcium influx (39), and lose membrane lipids to vesiculation $(3,4,6)$. Although the protein composition of the membrane of the stored cells remains normal, increased membrane-associated globin has been reported. In addition, spectrin-actin association in the presence of protein 4.1 becomes abnormal during storage (5). This change is independent of red cell ATP and may be secondary to oxidative damage. It has been suggested that the dissociation of membrane-bound globin into heme and iron results in a potent source of pro-oxidant materials that can subsequently cause oxidation of membrane proteins (40). The stabilization of hemoglobin, through its conversion to carboxyhemoglobin, prevents the formation of membrane-bound hemoglobin and the abnormalities in spectrin-actin association found during storage (8). However, a relationship between defects in membrane skeleton protein interactions and abnormally short posttransfusion viability remains to be established.

A significant amount of red cell membrane lipids is lost as the result of vesiculation during storage. There is a good correlation between decreased surface area due to lipid loss and decreased posttransfusion viability (41). The mechanism responsible for vesiculation in stored blood is unknown, although ATP depletion is likely to be involved (42). The oxidation of red cell membrane skeleton proteins can also lead to vesiculation during storage $(9,43)$.

The spontaneous flip-flop or transmembrane diffusion of phospholipids takes place within the lipid bilayer, although it is a very slow process (14). Thus, maintenance of phospholipid asymmetry in red cells is strongly dependent upon a Mg-ATPase, called the aminophospholipid translocase (14). This ATPdependent enzyme continuously pumps PS and PE from the outer to the inner leaflet of the bilayer. It contains sulfhydryl groups in critical domains, as shown by blockage of its activity by $N$-ethylmaleimide, and it can be permanently damaged by oxidizing compounds. Furthermore, if the level of free cytosolic calcium approaches the micromolar range, aminophospholipid translocase activity is inhibited (14, 15, 16, 37).

The metabolic characteristics of stored red cells include ATP depletion, oxidation, and calcium accumulation. Therefore, our finding that translocase activity is altered during storage is not surprising. Measurements of the inward movement of spin-labeled PE and PS show that the rate progressively decreases during storage and that the decreased rate correlates with the ATP depletion. However, additional mechanism or mechanisms appear to be involved, since repletion of cellular ATP restored aminophospholipid translocase activity to $\sim 80 \%$ of its original value after 1 mo and to $\sim 30 \%$ at the end of the storage period ( $66 \mathrm{~d}$ ). The mechanism responsible for this permanent alteration may involve oxidation of the aminophospholipid translocase.

Previous studies suggested that phospholipid asymmetry was altered in stored red cells $(44,45)$. In these studies, both PE and PS were hydrolyzed following incubation of red cells with phospholipase $C$ after 5 wk of storage. However, the use of phospholipase $\mathrm{C}$ to measure phospholipid asymmetry has been criticized in two respects (46). Phospholipase $C$ generates diacylglycerol, which is capable of scrambling membrane phospholipids and therefore affecting lipid organization. In addition, since only $2 \%$ of the phospholipids were hydrolyzed in fresh cells, it appears that phospholipase $\mathrm{C}$ is not a satisfactory probe to measure membrane phospholipid asymmetry. Despite these criticisms, the increased hydrolysis of membrane phospholipids by phospholipase $\mathrm{C}$ after storage would be consistent with altered membrane lipid organization. Our findings that PC translocation increased during storage suggest that storage results in a perturbation in membrane organization. Partial correction of transbilayer movement of PC by ATP repletion indicates that this perturbation is related only in part to ATP depletion. Oxidative damage of the cytoskeleton, as observed during storage, might very well contribute to this altered PC movement, because it has been shown that oxidants, such as diamide, scramble PC organization $(43,47)$.

It is remarkable that in spite of a progressive loss of cytosolic ATP and a clear decrease in aminophospholipid translocase activity, as revealed by the spin-labeled phospholipid assay, no significant redistribution of endogenous phospholipid could be measured after prolonged periods of storage using either phospholipase A2 and sphingomyelinase $\mathrm{C}$ or fluorescamine. In particular, no PS appeared on the outer leaflet, even when the stored blood was further incubated for several hours at $37^{\circ} \mathrm{C}$ to exhaustively deplete ATP. This high stability was also observed with fresh cells and confirms reports that long chain phospholipids have a slow transverse diffuse rate in a cholesterol containing lipid bilayer. It is probably not necessary to implicate cytoskeleton-phospholipid interaction to explain this stability in red cells since cytoskeleton depletion in red cell vesicles or in spherocytes does not appear to modify the lipid distribution $(20,21,48)$.

The data that we obtained on stored RBCs using spin-labeled phospholipids show that: $(a)$ the aminophospholipid translocase activity is diminished as indicated by the change in the initial slope of the outward-inward movement; $(b)$ the plateaus corresponding to the equilibrium distribution of the spin-labeled aminophospholipids are progressively shifted. If endogenous phospholipids behaved like the spin-labeled phospholipids, the phospholipase $\mathrm{A}_{2}$ assay would detect such change in lipid asymmetry. Therefore, the steady state transmembrane distribution of phospholipids with a short $\beta$ chain bearing a nitroxide is not exactly similar to that of endogenous long chain phospholipids. This is not a surprise, since the steady state depends both on the translocase activity and on the passive back-diffusion, and the passive diffusion is dependent upon the nature of the acyl chains (49). The spin-labels studies are nevertheless revealing because they demonstrate the partial dysfunction of the aminophospholipid translocase and a potential modification of endogenous phospholipid transmembrane asymmetry, which, if it exists, is below the level of detection using phospholipases or fluorescamine as probes of lipid asymmetry.

In our hands, the fraction of PS on the outer leaflet must be greater than $2 \%$ of the total phospholipid pool to be unambiguously detected. Since PS is not present on the outer monolayer of fresh normal cells, the appearance there of only a few percent of the total phospholipid pool could change the cell surface properties and yet not be detectable with our phospholipase assay. The experiments carried out by Tanaka and Schroit in 
which PS-enriched red cells were recognized by macrophages (22), required on the order of $2 \%$ of exogenous phospholipids initially located in the outer leaflet. However, since the fluorescent PS derivatives used in these experiments are substrate of the aminophospholipid translocase (50), the actual number of PS molecules recognized by the macrophages in Tanaka and Schroit's experiment are likely to have been below $2 \%$ of the total phospholipids in the outer leaflet.

In conclusion, we have demonstrated several abnormalities in phospholipid dynamics in stored RBCs. We have shown that there is progressive loss of aminophospholipid translocase activity and that this phenomenon is accompanied by lipid scrambling. Depletion of ATP appears to be the primary cause for the defect in translocase activity, although other mechanisms, including oxidation of the translocase, must be considered. In addition, changes in passive exchange of $\mathrm{PC}$ from the outer to the inner leaflet of the membrane were noted, suggesting alterations in membrane organization. Although modifications of the endogenous phospholipid organization by storage could not be detected with phospholipases, our results do not rule out the possibility that PS exposure on the outer leaflet plays a role in the shortened posttransfusion viability of stored RBCs, providing macrophages can recognize a very small fraction of the RBC phospholipids.

\section{Acknowledgments}

We would like to thank Mary Ann Schott and Charis Wagner for their expert technical assistance, Pierre Fellmann and Paulette Hervé for the gift of spin-labeled molecules, Valerie Guillet for performing some EPR measurements, and Françoise Giraud for helpful discussion. This work was supported by the National Institutes of Health grants HL27059 and DK-32094, and by the Centre National de la Recherche Scientifique (UA 526), the Université Paris VII, and the "Direction des Recherches et Etudes Techniques" du Ministère de la Défense (DRET 91079).

\section{References}

1. Mollison, P. L. 1979. The survival of transfused red cells. In Blood Transfusion in Clinical Medicine. Blackwell Scientific Publications, Oxford, UK. 20 pp.

2. Wolfe, L. 1985. The red cell membrane and the storage lesion. Clin. Haematol. 14:259-276.

3. Wolfe, L. C. 1989. Oxidative injuries to the red cell membrane during conventional blood preservation. Semin. Hematol. 26:307-312.

4. Wolfe, L. 1985. The membrane and the lesions of storage in preserved red cells. Transfusion (Philadelphia). 25:185-203.

5. Wolfe, L. C., A. M. Byrne, and S. E. Lux. 1986. Molecular defect in the membrane skeleton of blood bank-stored red cells. Abnormal spectrin-protein 4.1-actin complex formation. J. Clin. Invest. 78:1681-1686.

6. Rumsby, M., J. Trotter, D. Allan, and R. H. Michell. 1977. Recovery of membrane micro-vesicles from human erythrocytes stored for transfusion: a mechanism for the erythrocyte discocyte to spherocyte shape transformation. Biochem. Soc. Trans. 5:126-128.

7. Feuerstein, H., and D. Stibenz. 1982. Banking-related decline of erythrocyte $N$-acetyl-neuraminic acid and phospholipids. Haematologia. 15:205-209.

8. Wolfe, L., A. Byrne, and D. Chiu. 1987. The storage lesion of liquid preserved erythrocytes is blocked in vitro by treatment with carbon monoxide $(\mathrm{CO})$. Blood. 70(Suppl 1):335a.

9. Wagner, G. M., D. T.-Y. Chiu, J.-H. Qju, R. H. Heath, and B. H. Lubin. 1987. Spectrin oxidation correlates with membrane vesiculation in stored RBCs. Blood. 69:1777-1781.

10. Lochant, N., N. Noble, and B. Myrhe. 1984. Antioxidant metabolism during blood storage and its relationship to post-transfusion red cell survival. $\mathrm{Am}$. J. Hematol. 17:237-249.

11. Bosman, G. J. C. G. M., and M. M. B. Kay. 1988. Erythrocyte aging: A comparison of model systems for simulating cellular aging in vitro. Blood Cells (NY). 14:19-35.
12. Laczko, J., C. Feo, and W. Phillips. 1979. Discocyte-echinocyte reversibility in blood stored in CPD over a period of 56 days. Transfusion (Philadelphia). 19:378-388.

13. Op den Kamp, J. A. F. 1979. Lipid asymmetry in membranes. Annu. Rev. Biochem. 48:47-71.

14. Devaux, P. F. 1991. Static and dynamic lipid asymmetry in cell membranes. Biochemistry. 30:1163-1173.

15. Seigneuret, M., and P. F. Devaux. 1984. ATP-dependent asymmetric distribution of spin-labeled phospholipids in the erythrocyte membranes: relation to shape changes. Proc. Natl. Acad. Sci. USA. 81:3751-3755.

16. Schroit, A. J., and R. F. A. Zwaal. 1991. Transbilayer movement of phospholipids in red cell and platelet membranes. Biochim. Biophys. Acta. 1071:313329.

17. Sato, S. B., and S. Ohnishi. 1983. Interaction of a peripheral protein of the erythrocyte membrane, band 4.1 , with phosphatidylserine containing liposomes and erythrocyte inside out vesicles. Eur. J. Biochem. 130:19-25.

18. Williamson, P., R. Antia, and R. A. Schlegel. 1987. Maintenance of membrane phospholipid asymmetry. Lipid-cytoskeletal interactions or lipid pump? FEBS (Fed. Eur. Biochem. Soc.) Lett. 219:316-320.

19. Mombers, C., J. de Gier, R. A. Demel, and L. L. M. van Deenen. 1980. Spectrin phospholipid interaction: A monolayer study. Biochim. Biophys. Acta. 603:52-62.

20. Calvez, J. Y., A. Zachowski, A. Herrmann, G. Morrot, and P. F. Devaux. 1988. Asymmetric distribution of phospholipids in spectrin-poor erythrocyte vesicles. Biochemistry. 27:5666-5670.

21. Gudi, S. R., A. Kumar, V. Bhakuni, S. M. Gokhale, and C. M. Gupta. 1990. Membrane skeleton-bilayer interaction is not the major determinant of membrane phospholipid asymmetry in human erythrocytes. Biochim. Biophys. Acta. 1023:63-72.

22. Tanaka, Y., and A. J. Schroit. 1983. Insertion of fluorescent phosphatidylserine into the plasma membrane of red cells. Recognition by autologous macrophages. J. Biol. Chem. 258:11335-11343.

23. Schlegel, R. A., T. W. Prendergast, and P. Williamson. 1985. Membrane phospholipid asymmetry as a factor in erythrocyte-endothelial cell interactions. J. Cell. Physiol. 123:215-218.

24. McEvoy, L., P. Williamson, and R. A. Schlegel. 1986. Membrane phospholipid asymmetry as a determinant of erythrocyte recognition by macrophages. Proc. Natl. Acad. Sci. USA. 83:3311-3315.

25. Fadok, V. A., D. R. Voelker, P. A. Campbell, J. J. Cohen, D. L. Bratton, and P. M. Henson. 1992. Exposure of phosphatidylserine on the surface of apoptotic lymphocytes triggers specific recognition and removal by macrophages. $J$. Immunol. 148:2207-2216.

26. Schroeder, F. 1984. Role of membrane lipid asymmetry in aging. Neurobiol. Aging. 5:323-333.

27. Herrmann, A., and P. F. Devaux. 1990. Alteration of the aminophospholipid translocase activity during in vivo and artificial aging of human erythrocytes. Biochim. Biophys. Acta. 1027:41-46.

28. Dern, R., G. Brewer, and J. Wiorkowski. 1967. Studies on the preservation of human blood. II. The relationship of erythrocyte adenosine triphosphate levels and other in vitro measures to red cell storageability. J. Lab. Clin. Med. 69:968-978.

29. Repecci, A., D. Sondag-Phull, C. Betz, and A. André. 1984. Packed red blood cells stored in PAGGS-Sorbitol medium: in vitro and in vivo survival studies. Proc. ISBT Congr., XVIII, Munich. 174 (Abstr.).

30. Brown, A. J. 1982. ATP and ATPase determinations in red blood cells. In Red Cell Membrane. A Methodologic Approach. J. C. Ellory and J. D. Young, editors. Academic Press, London. 223-238.

31. Roelofsen, B. 1982. Phospholipases as tools to study the localization of phospholipids in biological membranes. A critical review. J. Toxicol. Toxin Rev. 1:87-197.

32. Verkleij, A. J., R. F. A. Zwaal, B. Roelofsen, P. Comfurius, D. Kastelijn, and L. L. M. van Deenen. 1973. The asymmetric distribution of phospholipids in the human red cell membrane. A combined study using phospholipases and freeze-etching electron microscopy. Biochim. Biophys. Acta. 323:178-193.

33. Rose, H. G., and M. Oklander. 1965. Improved procedure for the extraction of lipids from human erythrocytes. J. Lipid Res. 6:428-431.

34. Roelofsen, B., and R. F. A. Zwaal. 1976. The use of phospholipases in the determination of asymmetric phospholipid distribution in membranes. In Methods of Membrane Biology. Vol. 7. E. D. Korn, editor. Plenum Publishing Corp., New York. 147-177.

35. Rouser, G., S. Fleicher, and A. Yamamoto. 1970. Two-dimensional thinlayer chromatographic separation of polar lipids and determination of phospholipids by phosphorus analysis of spots. Lipids. 5:494-496.

36. Rawyler, A., B. Roelofsen, and J. A. F. Op den Kamp. 1984. The use of fluorescamine as a permeant probe to localize phosphatidylethanolamine in intact Friend erythroleukemic cells. Biochim. Biophys. Acta. 769:330-336.

37. Morrot, G., P. Hervé, A. Zachowski, P. Fellmann, and P. F. Devaux. 1989. Aminophospholipid translocase of human erythrocytes: phospholipid substrate specificity and effect of cholesterol. Biochemistry. 28:3456-3462. 
38. Laczko, J., C. Feo, and W. Phillips. 1980. Discocyte-echinocyte reversibility in blood stored in CPD over a period of 56 days. Transfusion (Philadelphia). 19:378-388.

39. Wiley, J. S., K. E. Mc Culloch, and D. S. Bowden. 1982. Increased calcium permeability of cold-stored erythrocytes. Blood. 60:92-98.

40. Hebbel, R. P. 1991. Beyond hemoglobin polymerization: the red blood cell membrane and sickle disease pathophysiology. Blood. 77:214-237.

41. Card, R., N. Mohandas, and P. Mollison. 1983. Relationship of posttransfusion-viability to deformability of stored red cells. Br. J. Haematol. 53:237240.

42. Clark, M., N. Mohandas, C. Feo, M. S. Jacobs, and S. B. Shohet. 1981. Separate mechanisms of deformability loss in ATP-depleted and Ca-loaded erythrocytes. J. Clin. Invest. 67:531-539.

43. Haest, C. W. M., G. Plasa, D. Kamp, and B. Deuticke. 1978. Spectrin as a stabilizer of the phospholipid asymmetry in human erythrocyte membranes. Biochim. Biophys. Acta. 509:21-32.

44. Little, C., and M. Rumsby. 1985. Lysis of erythrocytes from stored blood by phospholipase C. Biochem. J. 188:39-46.

45. Shukla, S. D., R. Colman, J. B. Finean, and R. H. Michell. 1978. The use of phospholipase $\mathrm{C}$ to detect structural changes in the membranes of human erythrocytes aged by storage. Biochim. Biophys. Acta. 512:341-349.

46. Van Meer, G., B. de Kruijff, J. A. F. Op den Kamp, and L. L. M. van Deenen. 1980. Preservation of bilayer structure in human erythrocytes and erythrocyte ghosts after phospholipase treatment-A 31 P-NMR study. Biochim. Biophys. Acta. 596:1-9.

47. Frank, P. F. H., J. A. F. Op den Kamp, B. Roelofsen, and L. L. M. van Deenen. 1986. Does diamide treatment of intact human erythrocytes cause a loss of phospholipid asymmetry? Biochim. Biophys. Acta. 857:127-130.

48. Kuypers, F. A., B. H. Lubin, M. Yee, P. Agre, P. F. Devaux, and D. Geldwerth. 1993. The distribution of erythrocyte phospholipids in hereditary spherocytosis demonstrates a minimal role for erythrocyte spectrin on phospholipid diffusion and asymmetry. Blood. 81:1051-1057.

49. Middelkoop, E., B. H. Lubin, J. A. F. Op den Kamp, and B. Roelofsen. 1986. Flip-flop rates of individual molecular species of phosphatidylcholine in the human red cell membrane. Biochim. Biophys. Acta. 855:421-424.

50. Colleau, M., P. Hervé, P. Fellmann, and P. F. Devaux. 1991. Transmembrane diffusion of fluorescent phospholipids in human erythrocytes. Chem. Phys. Lipids. 57:29-37. 